\title{
Selection of turbulence models in case of numerical simulation of heat-, air- and mass exchange processes
}

\author{
Vladimir Aver'yanov ${ }^{1}$,Vladimir Vasiliev $^{2}$, and Vera Ulyasheva $^{2, *}$ \\ ${ }^{1}$ Gazpromgaz JSC, 6 st., Nametkina, 117420, Moscow, Russia \\ ${ }^{2}$ Saint-Petersburg State University of Architecture and Civil Engineering, Department of engineering \\ ecology and municipal engineering, Sub-department - Heat and gas supply and ventilation, 4, \\ 2d Krasnoarmeiskaya Str., 190005 Saint-Petersburg, Russia
}

\begin{abstract}
Numerical experiment with the use of software products, such as Ansis, Star-CD, Star-CCM+ and other, helps get the fields of distributing parameters in different environments. In case of conducting numerical simulation one of the main tasks is to select the most appropriate turbulence model. This work presents analysis of results of numerical simulation of ventilation processes in production premises with spatial heat sources located on the platforms above floor level with the use of Spalart-Allmaras (SA) and $k-\varepsilon$ turbulence models as well as LES method. A comparison of results of full-scale experiment and numerical simulation has been performed. A turbulence model $k-\varepsilon$ has been used in numerical investigations of heat- and mass exchange processes in the nozzle of cellular humidifier of system of processing plenum air. The analysis of results of calculation and experimental data acquired at experimental installation is shown. The condition of microclimate in the working zone of premises significantly depends on the peculiarities of heat exchange through external building structures. This work presents results of numerical simulation of heat exchange through cold floors on the ground and in case of presence of underlining in the production premises with sources of heat emissions with the use of $k-\varepsilon$ turbulence model.
\end{abstract}

\section{Introduction}

A significant number of works of national and foreign authors, in particular [1-7] has been devoted to investigating processes of heat- and air exchange in the premises and heat- and mass exchange in the contact devices of air conditioning systems. The up-to-date level of developed software products, such as ANSYS, Star-CD and Star-CCM+, Fluent helps effect numerical simulation of quite complex heat- and mass exchange and hydrodynamic processes, including the field of ventilation and air conditioning.

\footnotetext{
${ }^{*}$ Corresponding author: ulyashevavm@mail.ru
} 
Two main approaches are distinguished in case of numerical simulation of viscous liquids flow (Table 1):

- Direct numerical simulation (DNS) - solving full Navier-Stokes equations;

- Simulation with the use of averaged Navier-Stokes equations, viz: with respect to time (RANS), with respect to space (LES), hybrid modifications (DES).

The analysis of Table 1 and results of investigations of other authors shows $[1,4]$ that generally the methods based on the use of method modifications (SRANS and URANS) are used for solving applied tasks of hydrodynamics with the use of different semi-empirical turbulence models as well as DES method also based on these models.

A system of differential equations of energy, continuity and preservation of pulse in the form of Navier-Stokes and admixture is the basis of numerical investigation of turbulent air flows in the premises with heat emission sources and admixtures:

$$
\begin{aligned}
& \frac{\partial \overline{\mathrm{u}}_{\mathrm{j}}}{\partial \mathrm{x}_{\mathrm{j}}}=0, \\
& \frac{\partial \overline{\mathrm{u}}_{\mathrm{i}}}{\partial \mathrm{t}}+\frac{\partial \overline{\mathrm{u}_{\mathrm{j}} \mathrm{u}_{\mathrm{i}}}}{\partial \mathrm{x}_{\mathrm{j}}}=-\frac{1}{\rho} \frac{\partial \overline{\mathrm{P}}}{\partial \mathrm{x}_{\mathrm{j}}}+\frac{\partial}{\partial \mathrm{x}_{\mathrm{j}}}\left(v \frac{\partial \overline{\mathrm{u}}_{\mathrm{i}}}{\partial \mathrm{x}_{\mathrm{j}}}\right)+\mathrm{g} \beta\left(\mathrm{T}-\mathrm{T}_{0}\right)+\frac{\partial}{\partial \mathrm{x}_{\mathrm{j}}}\left(\overline{\overline{\mathrm{u}_{\mathrm{i}}^{\prime} \mathrm{u}_{\mathrm{j}}^{\prime}}}\right) \\
& \frac{\partial \overline{\mathrm{T}}}{\partial \mathrm{t}}+\frac{\partial \overline{\mathrm{u}_{\mathrm{j}} \mathrm{T}}}{\partial \mathrm{x}_{\mathrm{j}}}=\frac{\partial}{\partial \mathrm{x}_{\mathrm{j}}}\left(\frac{\lambda}{\rho \mathrm{c}_{\mathrm{p}}} \frac{\partial \overline{\mathrm{T}}}{\partial \mathrm{x}_{\mathrm{j}}}\right)+\frac{\partial}{\partial \mathrm{x}_{\mathrm{j}}}\left(-\overline{\mathrm{T}^{\prime} \mathrm{u}_{\mathrm{j}}^{\prime}}\right) \\
& \frac{\partial \overline{\mathrm{C}}}{\partial \mathrm{t}}+\frac{\partial \overline{\mathrm{u}_{\mathrm{j}} \mathrm{C}}}{\partial \mathrm{x}_{\mathrm{j}}}=\frac{\partial\left(\overline{-\mathrm{u}_{\mathrm{j}}^{\prime} \mathrm{C}^{\prime}}\right)}{\partial \mathrm{x}_{\mathrm{j}}}+\mathrm{J}_{\mathrm{c}}
\end{aligned}
$$

Table 1. Methods of simulating turbulent flows $[1,4]$.

\begin{tabular}{|c|c|c|c|c|c|}
\hline $\begin{array}{c}\text { Method full } \\
\text { name }\end{array}$ & $\begin{array}{c}\text { Name in literature in } \\
\text { English }\end{array}$ & $\begin{array}{c}\text { Required mesh } \\
\text { points number }\end{array}$ & $\begin{array}{c}\text { Field of application at } \\
\text { present }\end{array}$ & $\begin{array}{c}\text { Methods characteristic } \\
\text { features }\end{array}$ \\
\hline $\begin{array}{c}\text { Direct numerical } \\
\text { simulation }\end{array}$ & $\begin{array}{c}\text { Direct Numerical } \\
\text { Simulation (DNS) }\end{array}$ & $10^{16}$ & $\begin{array}{c}\text { Calculating flows with } \\
\text { quite low Reynolds } \\
\text { numbers }\end{array}$ & $\begin{array}{c}\text { Solution of non- } \\
\text { stationary Navier-Stokes } \\
\text { equations }\end{array}$ \\
\hline \multicolumn{3}{|c|}{ Simulation with the use of averaged Navier-Stokes equations } \\
\hline $\begin{array}{c}\text { with respect to } \\
\text { time }\end{array}$ & $\begin{array}{c}\text { Reynolds Averaged } \\
\text { Navier-Stokes } \\
\text { (RANS) }\end{array}$ & $10^{7}$ & $\begin{array}{c}\text { Solution of wide range } \\
\text { of hydrodynamic tasks }\end{array}$ & $\begin{array}{c}\text { It is used in up-to-date } \\
\text { software products }\end{array}$ \\
\hline $\begin{array}{c}\text { with respect to } \\
\text { space }\end{array}$ & $\begin{array}{c}\text { Simulation (LES) } \\
\text { Large Eddy }\end{array}$ & $10^{11.5}$ & $\begin{array}{c}\text { Calculation of } \\
\text { meteorological tasks, } \\
\text { aero acoustics, } \\
\text { turbulent chemical } \\
\text { flows }\end{array}$ & $\begin{array}{c}\text { LES with near-wall } \\
\text { RANS simulation }\end{array}$ \\
\hline $\begin{array}{c}\text { hybrid } \\
\text { modifications }\end{array}$ & $\begin{array}{c}\text { Simulation (DES) } \\
\text { Detached-Eddy }\end{array}$ & $10^{8}$ & $\begin{array}{c}\text { Solution of wide range } \\
\text { of hydrodynamic tasks }\end{array}$ & $\begin{array}{c}\text { Combination of LES } \\
\text { and RANS ("smooth" } \\
\text { flow) }\end{array}$ \\
\hline
\end{tabular}

It is commonly known that in case of solving Navier-Stokes equations the turbulence simulation remains to be the main problem. Presently different turbulence models have been created, the basic provisions of the most widespread models are given in Table 2 . The classification of turbulence models is based on the order of closing (number of additional differential equations in partial derivatives), which changes within the limits of 0-12. 
The modifications of Spalart-Allmaras model (SA) comprises one differential equation for modified kinematic turbulent viscosity $\widetilde{v}$ :

$$
\frac{\mathrm{D} \widetilde{v}}{\mathrm{Dt}}=\mathrm{P}^{v}-\mathrm{D}^{v}+\frac{1}{\sigma}\left\{\nabla \cdot[(v+\widetilde{v})] \nabla \widetilde{v}+\mathrm{c}_{\mathrm{b} 2}[(\nabla \widetilde{v}) \cdot(\nabla \widetilde{v})]\right\}+\mathrm{f}_{\mathrm{t} 1} \Delta \mathrm{U}^{2}
$$

The models $k$ - $\varepsilon$ include Kolmogorov-Prandtl formula for turbulent viscosity, equations of transfer of kinetic energy of turbulent pulsations and speed of its dissipation. The kinematic turbulent viscosity will be determined according to formula:

$$
v_{\mathrm{t}}=\mathrm{C}_{\mu} \mathrm{f}_{\mu} \mathrm{k}^{2} \varepsilon
$$

Kinetic turbulence energy:

$$
\frac{\partial \mathrm{k}}{\partial \mathrm{t}}+\bar{v}_{\mathrm{j}} \frac{\partial \mathrm{k}}{\partial \mathrm{x}_{\mathrm{j}}}=\tau_{\mathrm{ij}} \frac{\partial \bar{v}_{\mathrm{i}}}{\partial \mathrm{x}_{\mathrm{j}}}-\varepsilon+\frac{\partial}{\partial \mathrm{x}_{\mathrm{j}}}\left[\left(v+\frac{v_{\mathrm{t}}}{\sigma_{\mathrm{k}}}\right) \frac{\partial \mathrm{k}}{\partial \mathrm{x}_{\mathrm{j}}}\right]
$$

Degree of turbulence dissipation:

$$
\frac{\partial \varepsilon}{\partial \mathrm{t}}+\bar{v}_{\mathrm{j}} \frac{\partial \varepsilon}{\partial \mathrm{x}_{\mathrm{j}}}=\mathrm{C}_{\varepsilon 1} \mathrm{f}_{1} \tau_{\mathrm{ij}} \frac{\varepsilon}{\mathrm{k}} \frac{\partial \bar{v}_{\mathrm{i}}}{\partial \mathrm{x}_{\mathrm{j}}}-\mathrm{C}_{\varepsilon 2} \mathrm{f}_{2} \frac{\varepsilon^{2}}{\mathrm{k}}+\frac{\partial}{\partial \mathrm{x}_{\mathrm{j}}}\left[\left(v+\frac{v_{\mathrm{t}}}{\sigma_{\varepsilon}}\right) \frac{\partial \varepsilon}{\partial \mathrm{x}_{\mathrm{j}}}\right]
$$

\begin{tabular}{|c|c|c|c|}
\hline Model description & Distinctive feature & Field of application & Remarks \\
\hline \multicolumn{4}{|c|}{ Algebraic models of } \\
\hline Prandtl & $\begin{array}{l}\text { Analogy of mixing } \\
\text { length in the flow and } \\
\text { length of free passage } \\
\text { of molecules }\end{array}$ & thin viscous layers & \\
\hline Baldwin-Lomax & $\begin{array}{c}\text { Different interrelation } \\
\text { of viscosity }\end{array}$ & detached flows & \\
\hline \multicolumn{4}{|c|}{ One-parameter models } \\
\hline $\begin{array}{l}v_{\mathrm{t}}-92 \text { (model of A.N. Gulyaev, } \\
\text { V.E. Kozlov, A.N. Sekundova) }\end{array}$ & $\begin{array}{l}4 \text { constants and } \\
\text { assumed setting of } \\
\text { turbulence scale }\end{array}$ & shear flows & \\
\hline $\begin{array}{c}\text { SA } \\
\text { model and SARC, SACC } \\
\text { (varieties of Spalart-Allmaras } \\
\text { model) }\end{array}$ & $\begin{array}{l}1 \text { differential equation } \\
\text { for turbulent viscosity }\end{array}$ & $\begin{array}{l}\text { Tasks of external } \\
\text { aerodynamics }\end{array}$ & Formul 2 \\
\hline \multicolumn{4}{|c|}{ Two-parameter models } \\
\hline $\begin{array}{l}k-\varepsilon \text { models of: } \\
\text { Launder-Sharma }\end{array}$ & $\begin{array}{l}\text { includes kinetic energy } \\
\text { of turbulence and speed } \\
\text { of its dissipation }\end{array}$ & $\begin{array}{l}\text { shear flows, different } \\
\text { engineering tasks }\end{array}$ & $\begin{array}{l}\text { Formula } \\
4,5\end{array}$ \\
\hline $\begin{array}{l}\quad k-\omega \text { models of: } \\
\text { Wilcox and Menter }\end{array}$ & $\begin{array}{l}\text { includes kinetic energy } \\
\text { of turbulence and speed } \\
\text { of its dissipation } \\
\text { specific with respect to } \\
\text { volume }\end{array}$ & flows with hard walls & \\
\hline $\begin{array}{l}\text { Shear Stress Transport or SST } \\
\text { (Menter model - combination } \\
\text { of } k-\omega \text { and } k-\varepsilon \text { models) }\end{array}$ & & $\begin{array}{c}\text { detached flows, flows with } \\
\text { a necessity of logging } \\
\text { pressure differential, } \\
\text { ejection of flows }\end{array}$ & \\
\hline
\end{tabular}

Table 2. Characteristic of some turbulence models. 
Closing coefficients $C_{\varepsilon 1}=1.44 ; C_{\varepsilon 2}=1.92 ; C_{\mu}=0.09 ; \sigma_{k}=1.0 ; \sigma_{\varepsilon}=1.3$

Two assumptions are used in LES method (simulation of large-scale vortexes):

- possibility of dividing speed field into motion of large-scale and small-scale vortexes;

- approximation of non-linear interactions between large-scale and small-scale vortexes.

\section{Theoretical analysis}

The software system Star-CD has been used for investigating state of air environment in the premises (production shop with heat emission sources, office premises), in this case moisture content has been adopted as an impurity [2]. A method of final volumes on structured non-orthogonal unbiased grid has been used for transition from differential equations to discrete ones. Traditionally, computational grid infills in the neighborhood of hard boundaries. The approximation of convection terms of equations (1) has been fulfilled with the use of counterflow diagram of the first order of accuracy. The pressure correction has been performed according to SIMPLEC algorithm. Generally, the adhesion conditions have been defined as boundary conditions for air velocities at the walls. The heat flow densities have been defined on surfaces, through which heat flow takes place. The velocity, temperature and air moisture content have been defined in air outlets. The calculation results with the use of above methods have been compared for assessing expediency of using LES method, Spalart-Allmaras (SA) and standard $k-\varepsilon$ turbulence models. Figure 1 shows the fields of air temperature distribution for one of the most characteristic sections of the production premises.
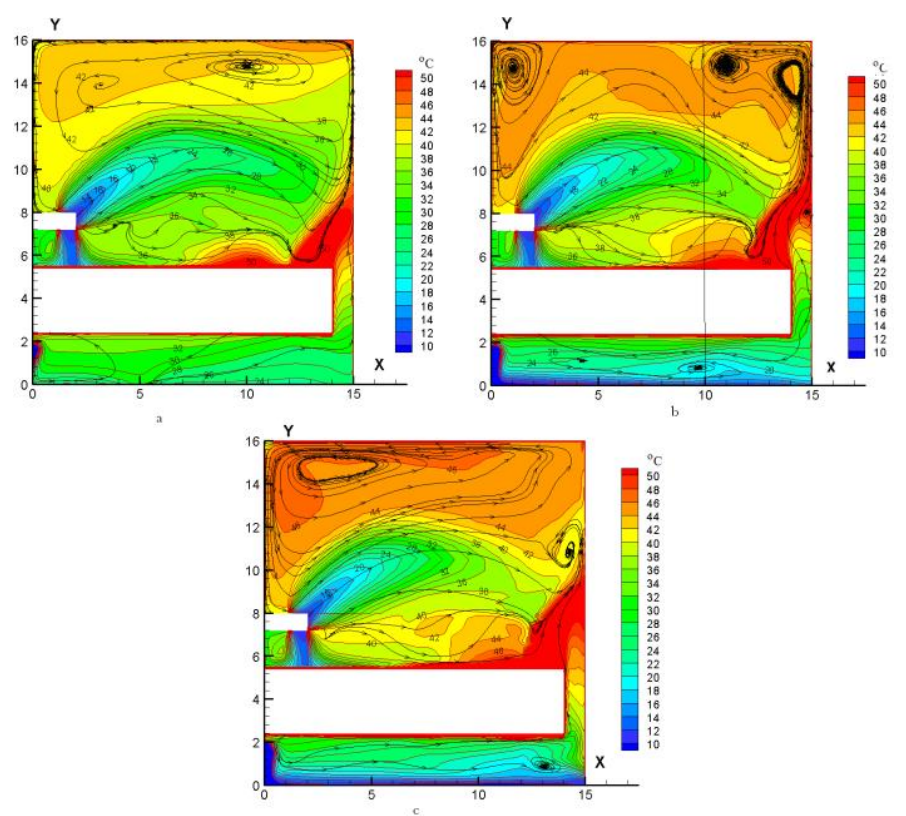

Fig. 1. Air temperature distribution proceeding from the results of numerical calculation with the use of turbulence models $k-\varepsilon$ (a), SA (b) and LES (c).

A satisfactory reproducibility of these fields for any section takes place, at that, labor content decreases significantly with the use of turbulence model SA, in this case Spalart-Allmaras turbulence model has been assumed for further numerical simulation. In order to assess adequacy of numerical investigation of processes of heat- and air exchange in the premises with heat emission sources, the results of full-scale investigations have been 
used. The results of numerical calculation presented in Figure 2 correlate with experimental data in a satisfactory way.
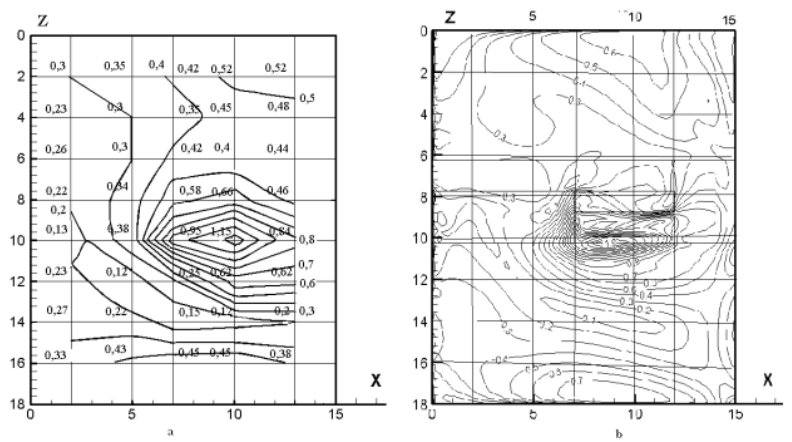

Fig. 2. Velocity of air Circulation in the working area of production premises during cold period: $\mathrm{a}$ - according to data of experimental investigations; $\mathrm{b}$ - proceeding from numerical simulation results.

In order to calculate the heat and mass exchange processes in the nozzle of cellular humidifier, Reynolds equations have been used for describing turbulent flows appended by the equations of convection-diffusion transfer for the averaged scalar substance $\bar{a}$ (temperature, water steam) similarly to system (1):

$$
\begin{aligned}
& \frac{\partial \bar{\rho}}{\partial \mathrm{t}}+\frac{\partial}{\partial \mathrm{x}_{\mathrm{j}}}\left(\bar{\rho} \overline{\mathrm{u}}_{\mathrm{i}}+\bar{\rho}^{\prime} \overline{\mathrm{u}}_{\mathrm{i}}{ }^{\prime}\right)=\mathrm{S}_{\mathrm{m}} \\
& \rho\left(\frac{\partial \overline{\mathrm{u}}_{\mathrm{i}}}{\partial \mathrm{t}}+\overline{\mathrm{u}}_{\mathrm{j}} \frac{\partial \overline{\mathrm{u}}_{\mathrm{i}}}{\partial \mathrm{x}_{\mathrm{j}}}\right)=-\frac{\partial \overline{\mathrm{P}}}{\partial \mathrm{x}_{\mathrm{j}}}+\mu\left(\frac{\partial \overline{\mathrm{u}}_{\mathrm{i}}}{\partial \mathrm{x}_{\mathrm{j}}}+\frac{\partial \overline{\mathrm{u}}_{\mathrm{i}}}{\partial \mathrm{x}_{\mathrm{i}}}\right)+\frac{\partial \tau_{\mathrm{ij}}{ }^{\prime}}{\partial \mathrm{x}_{\mathrm{j}}}+\mathrm{S}_{\mathrm{i}} \\
& \frac{\partial(\bar{\rho} \overline{\mathrm{a}})}{\partial \mathrm{t}}+\frac{\partial\left(\bar{\rho} \overline{\mathrm{au}}_{\mathrm{i}}\right)}{\partial \mathrm{x}_{\mathrm{j}}}=-\frac{\partial\left(\bar{\rho} \overline{\mathrm{u}}_{\mathrm{j}}{ }_{\mathrm{a}} \overline{\mathrm{a}}^{\prime}\right)}{\partial \mathrm{x}_{\mathrm{j}}}+\overline{\mathrm{J}}_{\mathrm{a}}
\end{aligned}
$$

The task under investigation has been solved with the use of software system Star-CCM+ [3]. Figure 3(a) shows a computational grid of model of a channel with cassette, at that, the grid infills significantly close to humidifier evaporation surfaces. $1 \mathrm{~mm}$ thick liquid film runs down the nozzle surface under the action of gravity. 5 iterations have been adopted for every step with respect to time. A finite volume method has been used for transition from differential equations to discrete ones.

$k-\varepsilon$ turbulence model has been used for solving the task. The calculation has been made under the following conditions: air temperature at channel inlet is $24^{\circ} \mathrm{C}$ and moisture content is $4.16 \mathrm{~g} / \mathrm{kg}$; temperature of water supplied into humidifier equals $16^{\circ} \mathrm{C}$. Figures 3 (b) and 3(c) show some results of numerical simulation. The distribution of evaporation intensity and change of film thickness helps to make a conclusion on a non-stationary character of evaporation process by the plate height and acquire quantitative characteristics. In order to evaluate reproducibility of numerical experiment, a monitoring of tracked parameters has been performed, which satisfactory results for evaporation intensity are shown in Figure 3(d). 


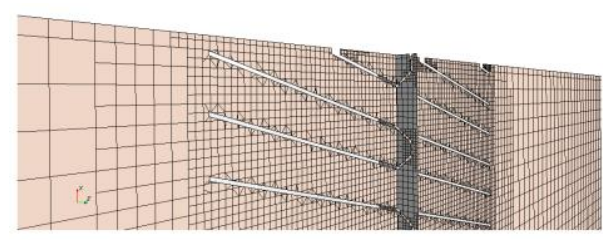

a

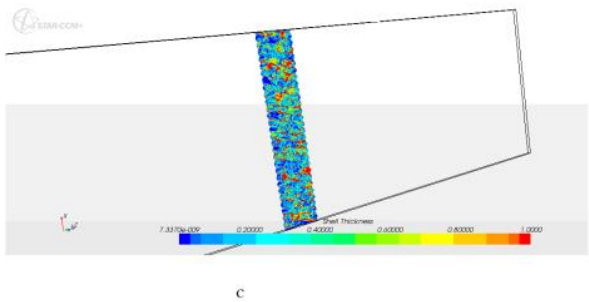

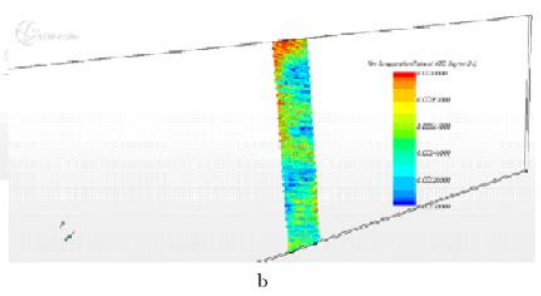

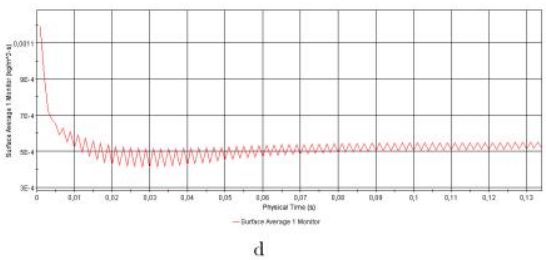

Fig. 3. Computational grid of channel with cassette for humidification (a); distribution of evaporation intensity (b); change of film thickness, $\mathrm{kg} / \mathrm{m}^{2} \cdot \mathrm{s}$ (c); reproducibility of evaporation intensity (d).

The comparison of results of author's numerical and laboratory experiments with experimental investigations of the other authors [5] reflects an identical character of dependence of evaporation intensity $I$ on the area of contact surface $F$. The evaporation intensity depends on the structure of filler material and method of laying it. The following approximating dependence has been obtained for the nozzle under investigation:

$$
I=0,005 \cdot e^{-0,115 \cdot F}
$$

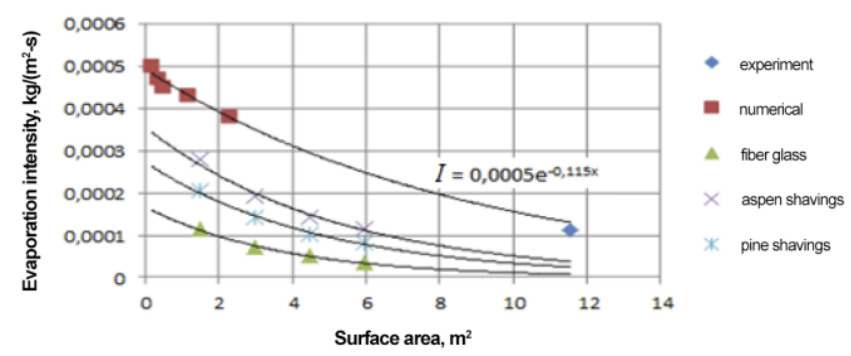

Fig. 4. Dependence of evaporation intensity $\left(\mathrm{kg} / \mathrm{m}^{2} \cdot \mathrm{s}\right)$, on area of heat and mass exchange surface.

The state of microclimate during cold period of the year in the premises of any purpose depends, first of all, on such factors as climatic characteristics, space-planning solutions, heat-shielding properties of building structures. A heating load on the systems of providing microclimate will be determined on the basis of the premises heat balance, which components will be the heat losses through outer shells proceeding from the resistance of different construction materials to heat transfer taking into account correction coefficients. In consideration of natural non-uniformity of soil temperature distribution, the heat losses through cold floor on the ground will be calculated by means of zoning method. Essential are the investigations of heat exchange through floors on the ground in hot shops with complex space-planning solutions, including machine halls of compressor stations with gasturbine plants (GTP). 
The GTP with gas ducts (Figure 5) are strong sources of heat emissions, which are located above the floor level owing to production process peculiarities, which contributes to forming a zone of low temperatures in the lower part of these premises.
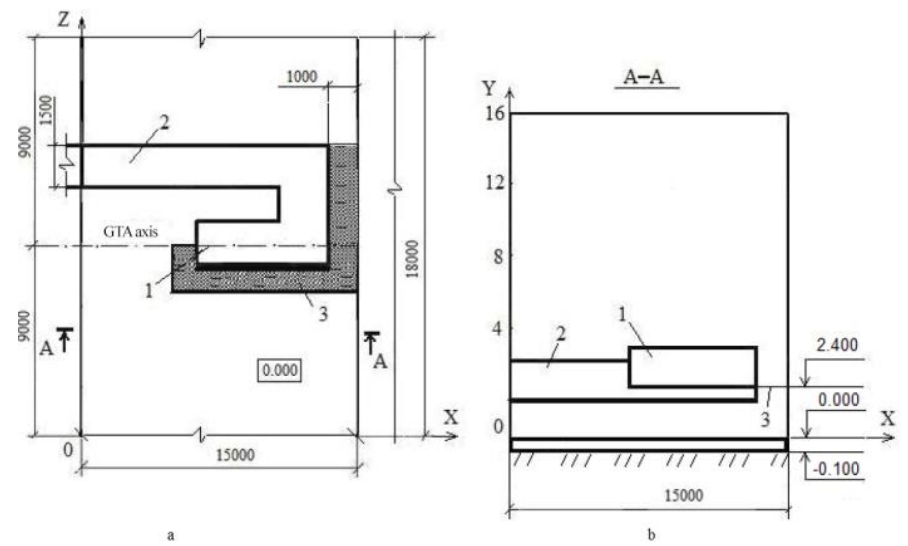

Fig. 5. Plan (a) of module of machine hall and section a-a (b) 1- gas-turbine plant, 2 - gas duct, 3 - maintenance platform.

This work presents the results of numerical experiment with the use of software system Star-CD. The investigations involve one of the most distributed turbulence models $k-\varepsilon$ in Kato Launder modification. The numerical simulation is based on the numeric system solution (1), similarly to the aforementioned a procedure of approximation and boundary conditions have been adopted. The following has been preset as additional boundary condition - average temperature on soil surface.

Figure 6 presents temperature fields in horizontal planes at el. $-0.001 \mathrm{~m}$ (a) and air at el. $+0.020 \mathrm{~m}(\mathrm{~b})$. The sections at $\mathrm{X}=0 \mathrm{~m}$ and $\mathrm{X}=15 \mathrm{~m}$ correspond to the inner surfaces of external walls. Black solid lines outline the areas located under the gas-turbine plant, gas duct and plenum units. The results of numerical experiment show that quite a uniform temperature field takes place at the depth of $0.001 \mathrm{~m}$ from the inner surface of cold floor. The temperature practically equals the temperature of soil at the level of $5-6^{\circ} \mathrm{C}$; it drops down to $0^{\circ} \mathrm{C}$ only within the limits of external walls. A different scene can be observed in case of giving consideration to air temperature distribution close to the inner surface of cold floor, e.g. at the level of $+0.020 \mathrm{~m}$. Extremely non-uniform temperature field can be observed in this plane with variation from $0^{\circ} \mathrm{C}$ to $20^{\circ} \mathrm{C}$, which, apparently, is connected with the specific features of arrangement of the heat-emitting equipment and radiation heat exchange. Figure 7 show temperature distribution along axis $\mathrm{Y}$ in the points with coordinates $X=3.0 \mathrm{~m}, Z=3.0 \mathrm{~m}$ and $X=13.0 \mathrm{~m}, \mathrm{Z}=3.0 \mathrm{~m}$. The data reflect identity of temperature variation character. The most intensive temperature change takes place at the boundary between hard surface and air. At that, the temperature differential is lower in points located in the neighborhood of the external wall with coordinate $X=0 \mathrm{~m}$ than in the neighborhood of an opposite wall. It is related to the fact that the external wall with coordinate $\mathrm{X}=0 \mathrm{~m}$ is characterized by high values of heat losses due to arrangement of process openings and gates. A presence of heat-release surfaces of gas-turbine plant provides for a more significant temperature differential in close proximity to the cold floor. 

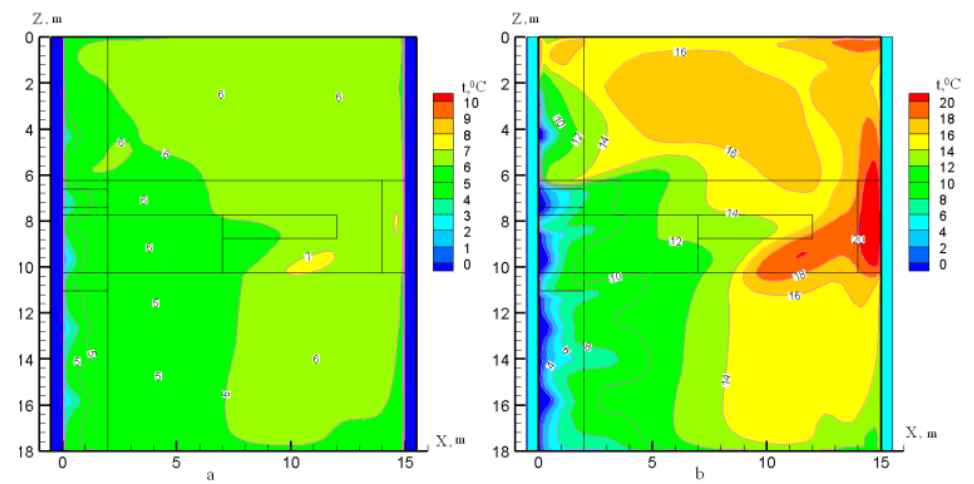

Fig. 6. Temperature distribution in the structure of cold floor at el. $-0.001 \mathrm{~m}$ (a) and air at el. $+0.020 \mathrm{~m}$ (b).
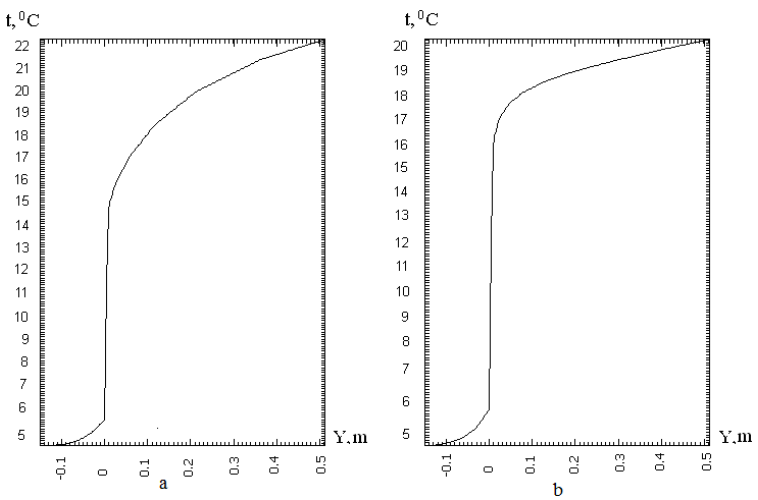

Fig. 7. Temperature distribution in point with coordinates $X=3.0 \mathrm{~m}, \mathrm{Z}=3.0 \mathrm{~m}$ (a) and $\mathrm{X}=13.0 \mathrm{~m}$, $\mathrm{Z}=3.0 \mathrm{~m}(\mathrm{~b})$.

\section{Conclusions}

A satisfactory reproducibility of results of calculating air parameters in production premises with heat sources has been obtained as a result of numerical simulation of processes of heat and air exchange in ventilated premises with the use of $L E S$ method, turbulence models SA and $k$ - $\varepsilon$. The practicability of using one-parameter turbulence model has been proven for investigating heat and air exchange in the premises.

In order to calculate the heat and mass exchange processes in contact apparatuses for plenum air processing, the adequate results have been acquired in case of using turbulence model $k-\varepsilon$. Proceeding from the results of numerical simulation the availability of criterial dependence for calculating Nusselt number determining the heat-exchanging processes in apparatus under investigation has been proven.

The results of numerical simulation of heat exchange through cold floor performed with the use of turbulence model $k-\varepsilon$ make it possible to come to a conclusion about quite uniform temperature distribution practically at the boundary with air environment, despite the existing essential non-uniformity of air temperature distribution in close proximity to the boundary surface. It reflects a weak influence of heat-releasing surfaces and air temperature spatial distribution in the premises to heat-exchanging processes through cold floors on the ground. The investigation results will be further used in calculating heat losses through cold floors on the ground and designing energy-efficient heating systems. 


\section{Nomenclature}

$t$ - time,

$\rho-$ density, $\mathrm{kg} / \mathrm{m}^{3} ; \quad \bar{u}_{\mathrm{j}}$-components of averaged speed vector along coordinate axes, $\mathrm{m} / \mathrm{s} ; v$-kinematic viscosity coefficient, $\mathrm{m}^{2} / \mathrm{s} ;\left(T-T_{0}\right)$ - departure of actual temperature from fixed, $\mathrm{K} ; \beta=T^{-1}-$ air temperature expansion coefficient, $\mathrm{K}^{-1} ; \bar{P}, \bar{T}, \bar{C}-$ averaged pressure, temperature and impurities concentration, $P a, K, \mathrm{~kg} / \mathrm{m}^{3} ; \overline{\mathrm{u}_{\mathrm{i}}^{\prime} \mathrm{u}_{\mathrm{j}}^{\prime}}=\frac{\tau_{\mathrm{ij}}}{\rho}$; $\tau_{\mathrm{ij}}$ - turbulent stresses, additional Reynolds stresses; $\rho c_{p} \overline{u^{\prime}{ }_{j} T^{\prime}}, \overline{u^{\prime}{ }_{j} C^{\prime}}$-additional heat flow and mass flow; $u_{i}^{\prime}, u^{\prime}{ }_{j}, T^{\prime}, C^{\prime}-$ local pulsations of velocity, temperature and flow impurities, $\mathrm{m} / \mathrm{s} ; J \mathrm{c}-$ intensity of impurity source, $\mathrm{kg} / \mathrm{s} ; P^{v}, D^{v}-$ generative and dissipative terms; $f_{t 1} \cdot \Delta U^{2}-$ term intended for initiating laminar-turbulent transition; $\sigma, c_{b 2}-$ model empirical constants; $\Delta U$ - module of velocity vectors difference. $\mu-$ coefficient of dynamic viscosity, $\mathrm{Pa} \cdot \mathrm{s} ; \bar{a}-$ averaged values of scalar value specific density; $S_{m}, S_{i}-$ intensity of sources of mass and pulse; $\bar{J}_{a}-$ intensity of impurity sources.

\section{References}

1. A.M. Grimitlin, AVOK Severo-Zapad, (2013)

2. G.M. Pozin, Magazine of Civil Engineering 32, 6 (2012)

3. M.A. Kanev, Modern problems of science and education 2 (2015)

4. A.V. Garbaruk, Izd-vo Politechn. Universiteta (2012)

5. V.K. Averyanov, S.M. Anisimov, M.A. Kanev, Vestnik grazhdanskikh inzhenerov Bulletin of Civil Engineers 58, 5 (2016)

6. W.K. Chow, Build.Serv.Eng.Res. and Technol. 16, 2 (1995)

7. H. Hattori, H. DNS, LES and RANS of Turbulent Heat Transfer in Boundary Layer with Suddenly Changing Wall Thermal Conditions 01.05.2013. http://dx.doi.org/10.1016/j.ijheatfluidflow.2013.03.014/ 